\title{
PALABRAS DEL DR. FRANCISCO PARDO VARGAS, PRESIDENTE DE FECOLSOG EN LA SESION INAUGURAL DEL CURSO CONMEMORATIVO 40 AÑOS REVISTA COLOMBIANA DE OBSTETRICIA Y GINECOLOGIA
}

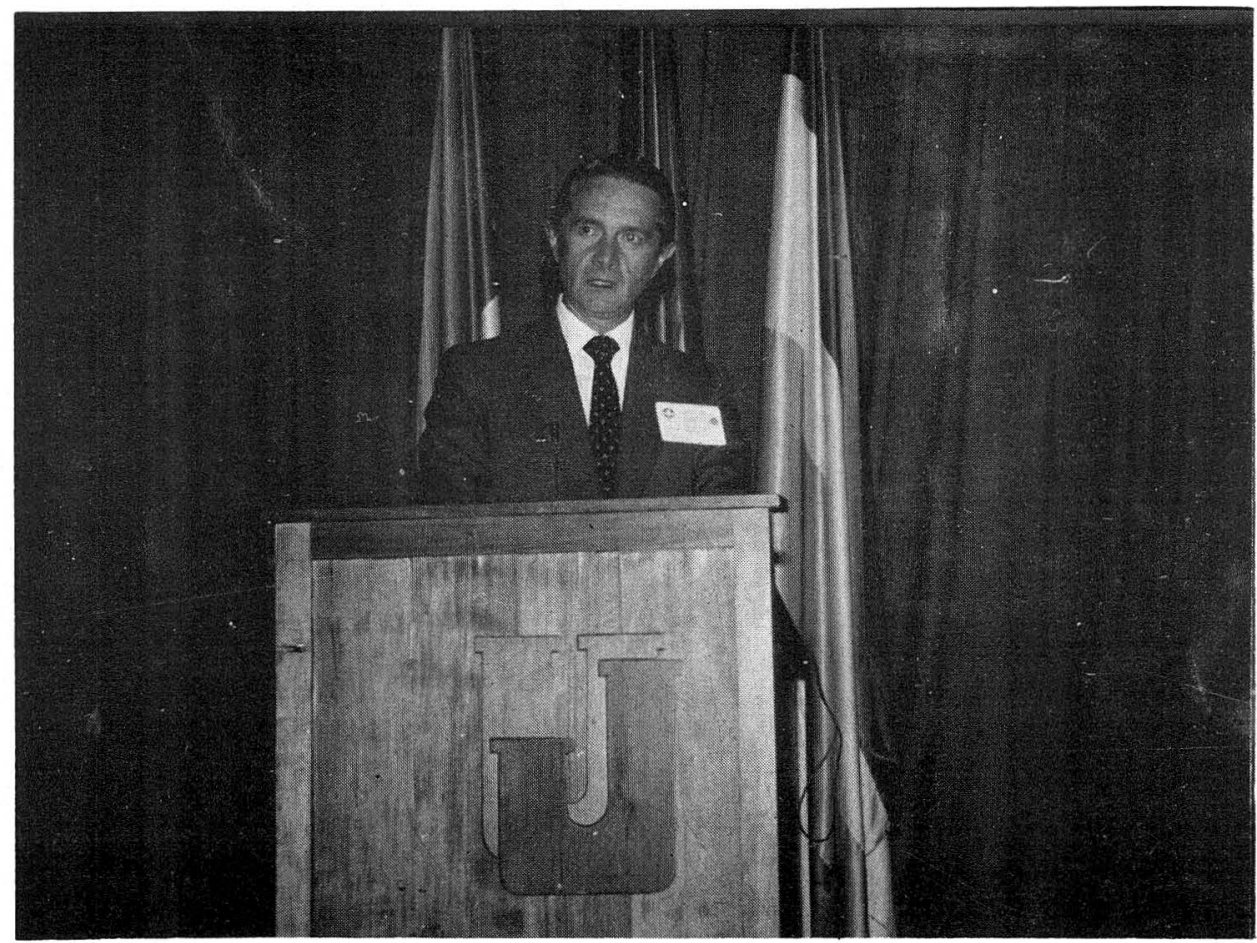

No podíamos dejar pasar desapercibidamente esta efemérides de los 40 años de publicación ininterrumpida de la Revista Colombiana de Obstetricia y Ginecología. Y pensamos que la mejor manera de celebrarla era congregados aquí, bajo el patrocinio de nuestra Revista y con el generoso y ya tradicional albergue de esta Universidad, para que todos juntos, generaciones de maestros y de discípulos, pero ante todo de colegas y amigos, pudiéramos compartir los beneficios científicos y el grato ambiente de alegre compañerismo que siempre ha caracterizado a nuestras reuniones.

Características y objetivos fundamentales de la Revista han sido el de servir como tribuna de divulgación a la producción científica nacional y la de ejercer una permanente cátedra de educación continuada. Acordes con tal espíritu, en esta celebración se ha invitado a un selecto grupo de expositores nacionales que nos presentarán sus conceptos y experiencias sobre interesantes temas de gran actualidad, y cuya colaboración quiero agradecer pública y sinceramente.

En verdad que no nos falta razón para tener una alegre reunión; porque lograr en nuestro medio que durante casi medio siglo se haya podido mantener la publicación regular de una revista científica es excepcional o cuando menos, insólito. Ya tendremos oportunidad de escuchar en la reseña histórica, hechos y circunstancias que hacen espe- 
cialmente meritoria su existencia. Quienes hemos tenido en algún momento la responsabilidad de dirigirla, bien sabemos las múltiples labores que se deben desempeñar en lo que aun recuerdo como una carrera contra reloj para poder cumplir oportunamente con su entrega: el laborioso proceso de recolección del material científico, la búsqueda incesante de esquivos y resbaladizos anunciadores, los múltiples viajes a la editorial de turno con el inevitable regateo a los costos de impresión, y la correción de las interminables cuartillas de las pruebas, son algunas de las silenciosas tareas que los Directores deben cumplir para lograr una publicación oportuna y acorde con el nivel científico de los suscriptores.

Para nadie es un misterio que toda publicación de una Sociedad Científica en nuestro medio, se encuentra sometida a tremendas dificultades económicas y la nuestra no ha escapado a esas viscisitudes. Publicada inicialmente y durante casi la mitad de su existencia bajo la responsabilidad exclusiva de los especialistas bogotanos a través de su Sociedad, la Revista fue fortalecida a partir de 1969 con la vinculación oficial de las demás Sociedades Regionales agrupadas desde ese momento en la recién fundada Federación Colombiana de Sociedades de Obstetricia y Ginecología. Desde entonces, en forma mancomunada y solidaria, ambas entidades se han comprometido a mantener avante la publicación y en épocas críticas le han prestado todo el apoyo requerido para sortear sus dificultades. Hoy en día, al cumplir los primeros 40 años de su existencia, la Revista se encuentra en buena situación, su mercado publicitario se ha acreditado y está asegurado por períodos adelantados lo cual permite una planeación presupuestal sobre bases reales que evita los tropiezos propios de la improvisación.

Esta situación de bonanza, que todos esperamos sea permanente, es el resultado de un largo proceso de laboriosa perseverancia, orientado por sus Directores, que a través de todo el tiempo le han prestado desinteresadamente su colaboración, y que hoy, en las personas de sus actuales Directores, deben sentirse dignamente representados, pues su gestión ha sido de fundamental importancia para consolidar el prestigio de la Revista y para trazarle nuevos rumbos a la publicación.

Señores asistentes: Las consideraciones anteriores me dan fundamento para darles este parte de optimismo. Por ello, como Presidente de la Federación Colombiana de Sociedades de Obstetricia y Ginecología, me complace profundamente declarar inaugurado este certámen conmemorativo.

Muchas gracias 